\title{
A vilania dos juros: O discurso do jornalismo econômico
}

Elizabeth Moraes Gonçalves", André Sathler Guimarães**

\section{Resumo}

O artigo caracteriza-se como uma pesquisa explicativa, com metodologia comparativa entre texto da mídia massiva e da mídia especializada, na perspectiva francesa da análise crítica do discurso. O objetivo geral é analisar a cobertura da midia sobre uma decisão do Conselho de Política Monetária - Copom. Os objetos de estudo foram uma reportagem do jornal Valor Econômico e uma reportagem do jornal Folha de $S$. Paulo, ambas as reportagens datadas de um dia após a reunião do Copom (16/09/04) e a Ata da 100. reunião do Copom (15/09/04). Embora a temática tenha reflexos na vida de todo cidadão, tanto o documento quanto a abordagem midiática envolvem um linguajar especifico, restrito a uma pequena parcela da população. A Ata da reunião é escrita em linguagem hermética, um exemplo do discurso primário. A Folha de S.Paulo tem o compromisso de abordar o assunto, traduzindo-o ao seu público mais massivo. Quanto ao Valor Econômico, existe uma identificação total do veiculo com o tema em pauta. É possivel avaliar que o sentido depende de toda uma rede construida pelo veiculo, o ponto de vista abordado não é específico da matéria analisada, o que justifica a importância de se conhecer as condições de produção para uma análise do discurso.

Palavras-chaves: Comunicação, Discurso, Mídia, Política.

\section{Abstract}

The article caracterizes itself as an explanatory research, with comparative methodology between massive media text and specialized media text, under the French perspective of critical speech analysis. The general purpose is to analise the coverage of the media about the decision of the Copom (Brazilian Monetan' Polic' Committe). The objectives of the study were based on a lext from the newspapers Valor Economico and another text from the Folha de S. Paulo, both dated the day after the Copom meeting (Sept 16, 2004) and the Minutes of the 100. Copom meeting (Sept 15, 2004). Allthough the subject has effects on the dail' life of even' citizen, both documents, the mimutes and the media approach, have a specific language, restricted to a small portion of the population. The meeting minutes is written in a strict language, a model of a priman' speech. The Folha de S. Paulo has the commitment to approach the subject, translating it to it s massine public: But for Valor Economicothere is a complete identification of the vehicle with the subject in question. It is possible to evaluate the the sense depends on a whole chain built by: the vehicte, the point of view is riot specific of the theme being analysed, and this confirms the importance of knowing the production conditions for a speech anabsis.

Keywords: Communication, Speech, Media, Politics

\footnotetext{
Docente do Programa de Pós-Craduação em Comunicação Social da UMESP e reșponsável pelo grupo de pesquisa "Estudos de Comunicação e Linguagem".

. Economista Coordenador do Curso de Administração - Habilitação em Gestão de Negócios Internacionais da FCN/UNIMEP. Mestrando em Comunicação Social na Universidade Metodista de Sảo Paulo.
} 


\section{Introdução}

Existem textos que têm um grande impacto sobre a sociedade de uma forma geral, por terem a peculiaridade de serem performativos, instituindo realidades que passam a afetar todả a população de um país. Esse é o caso das leis, por exemplo, e das decisões de algumas instâncias governamentais. Esses textos são caracterizados pelo discurso autorizado pelas Instituições oficialmente estabelecidas, trata-se do que Barthes (1987, p.97) chama de discurso encrático, 'um discurso conforme a doxa, submetido a códigos que são eles próprios as linhas estruturantes da sua ideologia'. Dada a sua repercussão, estes discursos são minuciosamente analisados, reproduzidos e comentados pela mídia.

Há diversos modos de dizer e, conseqüentemente, diversas formas de se interpretar o que é dito. Parte-se do pressuposto de que toda realidade transformada em linguagem é uma forma de interpretação ou uma representação desta realidade. Já que não existe texto neutro, sempre há interesses em torno de uma questão. Segundo Pêcheux (2002), 'o discurso não surge no vazio. $O$ discurso remete à formação discursiva que o originou e que é marcada por uma ideologia ali embutida. $\mathrm{Na}$ origem do processo discursivo, há uma formação discursiva permitindo as condições de sua existência'.

Todo falante ou escrevente tem uma intencionalidade, explícita em maior ou menor grau pela escolha lexical, ordenamento das frases, composição do paratexto, uso de operadores argumentativos ou simplesmente pela escolha do que dizer ou não dizer. Segundo Koch (1984, p.24), 'toda atividade de interpretação presente no cotidiano da linguagem fundamenta-se na suposição de que quem fala tem certas intenções ao comunicar-se. Compreender uma enunciação é, nesse sentido, apreender essas intenções'.

No caso dos textos escritos, particularmente, há vários indicativos que auxiliam na composição do sentido. Pinto $(1999$, p.22) argumenta que 'é na superfície dos textos que podem ser encontradas as pistas ou marcas deixadas pelos processos sociais de produção de sentido que o analista vai interpretar'. Prosseguindo em seu raciocínio, Pinto (1999, p.22) afirma que

o analista de discursos é uma espécie de detetive sóciocultural.

Sua prática é primordialmente a de procurar e interpretar vestígios que permitem a contextualização em três níveis: o contextosituacional imediato, o contexto institucional e o contexto sóciocultural mais amplo no interior dos quais se deu o evento comunicacional.

O objetivo geral do presente trabalho é analisar a cobertura da mídia sobre uma decisão do Conselho de Política Monetária - Copom. Parte-se de uma premissa de que é impossível compreender um texto apenas no seu 
sentido denotativo, há que se entender a situação do discurso e as suas condições de produção:

Os dizeres não são apenas mensagens a serem decodificadas. São efeitos de sentidos que são produzidos em condições determinadas e que estão de alguma forma presentes no modo como se diz, deixando vestígios que o analista de discurso tem de apreender. São pistas que ele aprende a seguir para compreender os sentidos aí produzidos, pondo em relação o dizer com sua exterioridade... (ORLANDI, 2003, p.30).

Segundo Van Dijk (1992, p.122-124),

é plausível que as formas estruturais e os sentidos globais de um texto informativo ou noticioso não são arbitrários, mas o resultado de hábitos sociais e profissionais de jornalistas em ambientes institucionais, de um lado, é uma condição importante para o processamento cognitivo eficaz de um texto informativo ou noticioso, tanto por jornalistas como por leitores, de outro.

No caso estudado, tem-se, no contexto situacional imediato, a divulgação de uma decisão de um órgão governamental responsável pela definição da taxa de juros, instrumento clássico de execução da política monetária.

No contexto institucional, há uma forte discussão sobre a taxa de juros adequada à economia nacional, que extrapolou o âmbito das ciências cconômicas, tendo a questão dos juros se tornado a principal pauta do jornalismo econômico nos últimos anos. Em termos do contexto sócio-cultural, há um sentimento social de que a economia não cresce ou cresce em níveis insuficientes para se traduzir em uma situação mais folgada para as famílias, e que o grande vilão do momento são os juros. Por outro lado, o governo petista elegeu-se com uma plataforma de mudança, porém, deu continuidade à política econômica do governo anterior. cujo principal baluarte. ao menos no momento da transição, era os juros.

\section{Metodologia}

Tiata-se uma pesquisa explicativa, com utilização de um método comparativo, mediante o instrumento metodológico da análise crítica da linguagem e do discurso da comunicação jornalística, com ênfase na linha francesa. Buscou-se, conforme orientação teórica de Bacegga (1998:91), ir ao 'texto para extrair o sentido, mas para apreender a sua historicidade, o que significa se colocar no interior de uma relação de confronto de sentidos'. 
Entre o texto da Ata do Copom, pretensamente objetivo e formal, e a -interpretação que a mídia faz do mesmo, seja a mídia massiva, seja a especializada, ocorre, nitidamente, um confronto de sentidos.

Desta forma, a Análise do discurso representa uma nova abordagem do estudo do texto além da linearidade, relacionando enunciado e enunciação como elementos fundamentais da produção de sentido: 'esta distinção enunciação/ enunciado é apenas um exemplo da concepção da linguagem com o objetivo da constituição de uma teoria da linguagem como produção... O sujeito e o sentido não existem, produzem-se no trabalho discursivo.' (KRISTEVA, 1988, P.316).

\section{Como ressalta Santaella (1996, p.330)}

As linguagens não são inocentes nem inconseqüentes. Toda linguagem é ideológica, porque ao refletir a realidade, ela necessariamente a refrata. Há sempre, queira-se ou não, uma transfiguração, uma obliqüidade da linguagem em relação àquilo a que ela se refere.

Para Charaudeau (2003, p.67) o fundamento de todo discurso são as condições enunciativas, responsáveis por permitirem que certo mecanismo de comunicação social possa produzir sentido: 'el discurso informativo está

118 basado en la finalidad de "dar a conocer", que depende del modo como son utilizados los saberes de conocimiento y de creencia, y de los efectos de verdad escogidos por el informador'.

Na concepção de Bakhtin, há que se entender que o texto não pode ser tomado como simples objeto de análise, sem se considerar o dialogismo e a contextualização, ou seja, deve-se ter presente

a complexa interdependência que se estabelece entre o texto (objeto de análise e de reflexão) e o contexto que o elabora e o envolve (contex̀to interrogativo, contestatório, etc) através do qual se realiza o pensamento do sujeito que pratica ato de cognição e de juízo. ... é impossível eliminar ou neutralizar nele (no texto) a segunda consciência, a consciência de quem toma conhecimento dele. (BAKHTIN, 1997, p.333).

Os objetos de estudo do presente artigo foram uma reportagem do jornal Valor Econômico, considerado como mídia especializada, uma reportagem do jornal Folha de S. Paulo, considerado como mídia massiva, ambas as reportagens datadas de um dia após a reunião do Copom (16/09/04) e a Ata da 100. ${ }^{\mathrm{a}}$ reunião do Copom (15/09/04). 


\section{Quadro 1 - Objetos de Estudo}

\begin{tabular}{l} 
Ata da $100 .{ }^{2}$ Reunião do COPOM \\
\hline Folha de S. Paulo, edição de $16 / 09 / 2004:$ "BC inicia ajuste e juros \\
sobem para 16,25\%. Linha fina: TENSÃO PÓS-COPOM Elevação da taxa é \\
a primeira em 19 meses; Banco Central diz que esse é o começo de um \\
processo de alta.
\end{tabular}

- Valor Econômico, edição de 16/09/2004: "Copom cumpre ameaça e sobe juro. Linha fina: Novo arrocho BC eleva Selic para 16,25\% e alega que isso preserva o crescimento sustentado.

Trata-se, portanto, de uma metodologia comparativa entre texto da mídia massiva e da mídia especializada, na perspectiva francesa da análise do discurso, ou seja, a análise dos textos considerando suas condições de produção. Segundo Orlandi (1987:52), não é possível 'analisar o texto como uma seqüência lingüística fechada sobre ela mesma, porém é necessário referilo ao conjunto de discursos possíveis a partir de um estado definido de condições de produção'.

Barros (2002, p.5) lembra-nos que este tipo de abordagem visa integrar, por meio da enunciação, uma abordagem interna do texto, indispensável para que se reconheçam os mecanismos e regras de engendramento do discurso, com a análise externa do contexto sócio-histórico, em que o texto se insere e de que, em última instância, cobra sentido.

\section{O COPOM: As condições de produção}

Inspirado na experiência do Bundesbank (Banco Central da Alemanha). o Copom se reuniu pela primeira vez em 26 de junho de 1996. A reunião de 15/ 09 foi sua centésima reunião. Credita-se a idéia de sua criação ao economista Francisco Lopes ${ }^{76}$, que afirmou ter como objetivo criar um ritual para as decisões sobre política monetária, que antes eram tomadas 'em conversas de elevador' entre o diretor de política monetária e o presidente do Banco Central. Conforme afirmação do próprio Francisco Lopes: 'Achei que era necessário criar um ritual, acabar com aquela coisa de discutir no elevador' 77 . Essa perspectiva transparece na descrição oficial do surgimento e do objetivo do Conselho:

O Copom foi instituído em 20 de junho de 1996, com o objetivo de estabelecer as diretrizes da política monetária e de definir a taxa de juros. A criação do Comitê buscou proporcionar maior transparência e ritual adequado ao processo decisório, a exemplo do que já era adotado 
pelo Federal Open Market Committee (FOMC) do Banco Central dos Estados Unidos e pelo Central Bank Council, do Banco Central da Alemanha. Em junho de 1998, o Banco da Inglaterra também instituiu o seu Monetary Policy Committee (MPC), assim como o Banco Central Europeu, desde a criação da moeda única em janeiro de 1999. Atualmente, uma vasta gama de autoridades monetárias em todo o mundo adota uma prática semelhante, facilitando o processo decisório, a transparência e a comunicação com o público em geral. ${ }^{78}$

Interessante observar o comentário de que, em suas primeiras reuniões, o Copom despertava quase nenhuma atenção, até mesmo entre os seus membros, que tinham que ser lembrados das reuniões por telefone. Esse fato relaciona-se diretamente com as condições de produção do texto do Copom. Durante a década de 1980 e início dos anos 1990, o país conviveu com um processo hiperinflacionário. Por consequiência, o discurso do jornalismo econômico volta-se com grande intensidade para o tema da inflação, então escolhida, pela mídia, como inimigo número um do público. Após o Plano Real, houve o controle da inflação e surgiu um novo vilão para a cobertura econômica da mídia, o câmbio, cujo debate preencheu páginas e páginas dos jornais e revistas; tendo, inclusive, sido um dos fatores decisivos no processo de reeleição de Fernando Henrique Cardoso, em 1999. Com a desvalorização 120 cambial e a adoção do câmbio flutuante, a mídia viria a escolher um novo vilão: os juros.

O responsável pela definição dos juros era o Copom, conforme declarado em seus objetivos:

Formalmente, os objetivos do Copom são "implementar a política monetária, definir a meta da taxa Selic e seu eventual viés, e analisar o "Relatório de Inflação". A taxa de juros fixada na reunião do Copom é a meta para a taxa Selic (taxa média dos financiamentos diários, com lastro em títulos federais, apurados no Sistema Especial de Liquidação e Custódia), a qual vigora por todo o período entre reuniões ordinárias do Comitê..$^{79}$

Nos últimos anos, as reuniões do Copom têm sido sistematicamente acompanhadas e cobertas pela mídia, como ocorre, aliás, em outras partes do mundo. As decisões do Federal Reserve-FED, o Banco Central Americano, por exemplo, são aguardadas por agentes econômicos do mundo inteiro, afetando todos os demais países. Essa atenção da mídia é tão grande que levou, inclusive, o Presidente Lula a, recentemente, cunhar mais uma de suas frases peculiares: 'às vésperas da reunião do Copom o país vive uma tensão pré-Copom'. 
O Conselho é composto pelos membros da Diretoria Colegiada do Banco Central do Brasil: o presidente, que tem o voto de qualidade; e os diretores de Política Monetária, Política Econômica, Estudos Especiais. Assuntos Internacionais, Normas e Organização do Sistema Financeiro, Fiscalização, Liquidações e Desestatização, e Administração. Também participam do primeiro dia da reunião os chefes dos seguintes Departamentos do Banco Central: Departamento Econômico (Depec), Departamento de Operações das Reservas Internacionais (Depin), Departamento de Operações Bancárias e de Sistema de Pagamentos (Deban), Departamento de Operações do Mercado Aberto (Demab), Departamento de Estudos e Pesquisas (Depep), além do gerente-executivo da Gerência-Executiva de Relacionamento com Investidores (Gerin). Integram ainda a primeira sessão de trabalhos três consultores e o secretário-executivo da Diretoria, o assessor de imprensa, o assessor especial e, sempre que convocados, outros chefes de departamento convidados a discorrer sobre assuntos de suas áreas.

Conforme descrito no site do Banco Central do Brasil, as reuniões do Conselho são realizadas em dois dias. No primeiro dia das reuniões, os chefes de departamento e o gerente-executivo apresentam uma análise da conjuntura doméstica abrangendo inflação, nível de atividade, evolução dos agregados monetários, finanças públicas, balanço de pagamentos, economia internacional, mercado de câmbio, reservas internacionais, mercado monetário, operações de mercado aberto, avaliação prospectiva das tendências da inflação e expectativas gerais para variáveis macroeconômicas.

No segundo dia da reunião, participam apenas os membros do Comitê e o chefe do Depep, sem direito a voto, os diretores de Política Monetária e de Política Econômica. Esses dois diretores, com base nos dados apresentados no dia anterior, fazem suas recomendações acerca da política monetária. Em seguida, os demais membros do Copom fazem suas ponderações e apresentam eventuais propostas alternativas. Ao final, procede-se à votação das propostas, buscando-se, sempre que possível, o consenso. A decisão final a meta para a taxa Selic e o viés, se houver - é imediatamente divulgada à imprensa ao mesmo tempo em que é expedido o comunicado através do Sistema de Informações do Banco Central (Sisbacen). Essa providência é importante, pois, por se tratar de decisão crucial com impactos diretos sobre todos os agentes econômicos, há a necessidade de publicidade e transparência. com o intuito de se evitar ganhos ilícitos por informações privilegiadas.

As aias em português das reuniões do Copom são divulgadas às $8 \mathrm{~h} 30$ da quinta-feira da semana posterior a cada reunião, dentro do prazo regulamentar de seis dias úteis, sendo publicadas na página do Banco Central na Internet. Interessante observar essa dissociação temporal entre a reunião e a divulgação da Ata, que se reflete fortemente na concepção do documento, que se apresenta mais como um registro das informações analisadas pelos membros do que das discussões propriamente ditas. 


\section{$A$ ata da $100^{\mathrm{a}}$ reunião}

A Ata da reunião do Copom é escrita em linguagem formal, hermética, e abrange os seguintes tópicos: evolução recente da inflação, avaliação prospectiva das tendências da inflação, implementação da política monetária, atividade econômica, mercado de trabalho, crédito e inadimplência, ambiente externo, comércio exterior e alguns resultados do balanço de pagamentos, mercado monetário e operações de mercado aberto. Apresenta data, local, horários, relação dos presentes, diferenciando membros e demais participantes.

A parte efetivamente de registro textual da reunião é iniciada com a seguinte afirmação: 'Os membros do Copom analisaram a evolução recente e as perspectivas para a economia brasileira e para a economia internacional, no contexto do regime de política monetária, cujo objetivo é atingir as metas fixadas pelo governo para a inflação'. A primeira parte da frase transmite um claro efeito de clarividência, como se fossem "iluminados" os membros do Copom, que conseguem enxergar além dos outros e tomar uma decisão que afetará a vida da população do país inteiro, aliás, há que se destacar que realmente a posição ocupada pelos membros do conselho, assim como dos líderes políticos em geral, pressupõe um poder de decisão. A arrogância inicial é contrabalançada, contudo, pelo final da frase, que situa a discussão no âmbito do regime da política monetária e destaca o objetivo de se atingir as metas para a inflação, colocando o Conselho na defensiva, como que 122 justificando antecipadamente as suas decisões.

Ao longo do texto, ressaltam-se vários exemplos de utilização despropositada de linguagem excessivamente hermética (ex: "adversidades meteorológicas" ao invés de problemas com o clima), sinalizando para um não desejo de que o documento seja lido e entendido, o que pode ser também interpretado como uma postura defensiva, ou, por outro lado, como uma confirmação de arrogância de seus clarividentes membros que esperam que todos sejam capazes de compartilhar de seu "nível de linguagem". Entendemos que se trata de um exemplo evidente do discurso primário, ou seja, aquele que visa comunicar apenas aos seus pares.

Sobretudo nos dois primeiros tópicos, "evolução recente da inflação" e "avaliação prospectiva das tendências da inflação", são apresentados inúmeros dados, muitas vezes contrastantes entre si e paradoxais, não permitindo se chegar a uma conclusão definitiva sobre a sua evolução conjunta. Porém, ao longo do texto, os redatores da Ata direcionam o entendimento para uma tendência de aumento da inflação: 'Há, portanto, potencial significativo de impacto defasado sobre o IPCA dos próximos meses'; 'Persiste, todavia, a tensão decorrente do distanciamento da evolução de preços dos produtos industriais nos segmentos atacadista e varejista'; 'No mesmo sentido, permanece indefinido o cenário internacional dos preços de petróleo', são exemplos de frases inseridas ao longo do texto que 
direcionam o leitor para uma compreensão de que a tendência de alta da inflação é inequívoca.

Em outro momento, os redatores da Ata revelam novamente sua pretensão a uma clarividência, e sua subestimação a um possível público leitor: 'A intensidade desse repasse [aceleração recente dos preços industriais] dependerá, evidentemente, das condições vigentes de demanda final com que se depararão os setores envolvidos'. Não há nada de evidente no texto anterior, tampouco na linguagem utilizada. A utilização da palavra, nesse contexto, remete claramente a um sentido de superioridade ou a um discurso encrático, para lembrar a terminologia utilizada por Barthes ao abordar a divisão das linguagens com base nas noções de grupo e classes sociais:

A linguagem encrática é vaga, difusa, aparentemente 'natural' e. portanto, pouco identificável: é a linguagem da cultura de massa (imprensa, rádio, televisão) (...); toda essa linguagem encrática é ao mesmo tempo clandestina (não podemos reconhecê-la facilmente) e triunfante (não podemos escapar-lhe): direi que ela é pegajosa. A linguagem acrática, essa, é separada, cortante, desligada da doxa (é portanto paradoxal); a sua força de ruptura vem-lhe de ser sistemática, construída sobre um pensamento, não sobre uma ideologia.(BARTHES, 1987, p. 98).

Em uma frase lapidar, o Copom parece justificar, sinteticamente, sua decisão, utilizando-se do operador argumentativo "embora" para se colocar na defensiva: 'embora seja plausível que alguma acomodação espontânea esteja de fato em curso ou a caminho' (argumento possivel, a partir das evidências levantadas sobre as tendências da inflação), "não há elementos que indiquem de antemão uma tendência de acomodação suficientemente intensa para afastar preocupações com o perigo de descompasso entre a demanda e a oferta, e seus reflexos sobre a dinâmica dos preços. dado o patamar de produção já alcançado' (argumento definitivo em favor de que há uma tendência de alta da inflação).

Pode-se notar que por meio dos operadores argumentativos, "elementos que determinam o valor argumentativo dos enunciados, constituindo-se, pois. em marcas lingüísticas importantes da enunciação' (KOCH,1984, p.105) é possível identificar a formação discursiva dos textos que se constituem em um todo heterogêneo e complexo, a partir do momento em que sofrem interferências diversas de sujeito.

Outro sentido que os redatores da Ata tencionam transmitir é o da inexorabilidade da ação do Copom, como que a transferir a "culpa" de uma decisão "ruim" para entes abstratos, como tendências inflacionárias, comportamento de variáveis da política monetária, entre outros. Observa-se essa tentativa em exemplos como: 
Estimativas do Copom indicam que a inércia inflacionária teria, na ausência de reação da política monetária, um impacto de 0,9 ponto percentual sobre a inflação do IPCA em 2005; Os membros do Copom concordaram que, mantendo-se inalterada a postura da política monetária, a forte expansão da atividade econômica não apresenta sinais de estar em processo espontâneo de acomodação para um ritmo de preenchimento do hiato do produto compatível com a convergência da inflação para sua trajetória de metas (grifos nossos).

No primeiro exemplo, o uso do tempo verbal do futuro do subjuntivo do verbo ter - "teria" - associado a uma frase intercalada explicativa "na ausência de reação da política monetária", revela essa perspectiva de constrangimento à ação por parte do Conselho. Importante destacar o uso da palavra "reação", reage-se contra alguma coisa, algo que já aconteceu, está determinado. E, também, o complemento "da política monetária". Quem reage é o Copom, as pessoas que compõem o Conselho e dão os seus votos. A personificação intencional da política monetária tem o propósito específico de despersonalizar a decisão ou atenuar a consciência dos membros do Conselho. No segundo exemplo, novamente uma frase explicativa, restringindo o sentido - 'mantendo-se inalterada a postura da política monetária' - para sinalizar para a necessidade de uma alteração, caso contrário, o que já aconteceu trará impactos fortes sobre a economia, desestabilizando-a. Optou-se por transcrever a frase inteira, para que se possa observar, igualmente, o seu nível de hermeticidade, em um documento que se pretende "evidente".

Impressiona ao longo da Ata a profusão de afirmativas categóricas, transmitindo um sentido de certeza absoluta. Vale ressaltar que há profundas controvérsias entre economistas sobre o efeito das taxas de juros na economia, sua defasagem temporal, dentre outros fatores. Na realidade, a Economia não pode ser considerada uma ciência exata, embora alguns assim o pretendam e venham crescendo as análises de ênfase estatística e econométrica no campo da Economia. Contudo, os modelos econômicos continuam a ser isso, modelos, ou seja, representações simplificadas da realidade, que somente funcionam com a condição do ceteris paribus, ou seja, tudo o mais deve permanecer constante. No tocante à própria questão dos juros, vale mencionar o caso japonês, que chegou a praticar taxa nula de juros, sem lograr obter os efeitos pretendidos de crescimento econômico ${ }^{80} \mathrm{Um}$ exemplo de afirmação categórica, que só poderia ser feita se a economia fosse aplicada em um laboratório com condições ideais de temperatura e pressão: 'A fixação de tal objetivo neste momento deve-se ao fato de que a política monetária atua com defasagens temporais sobre a atividade e sobre a inflação e, por isso, é necessário calibrá-la com a devida antecipação de forma a obter os efeitos desejados'. 
Em determinado momento, o Conselho alerta que a situação poderia ser pior e, caso piorasse, a "reação" também seria pior. Esse tipo de alerta, comum em Atas anteriores, será traduzido, pela mídia, conforme será demonstrado, como "ameaça": "Se os dados correntes já permitissem identificar sinais de descontrole inflacionário ou de pressões excessivas de demanda, o ajuste na política monetária não poderia ser feito nas bases que estão sendo consideradas pelo Comitê'. O uso do condicional "se" e depois do "já" compõe uma frase que sinaliza quase que para um desejo de que a situação estivesse pior, para que o Copom pudesse "reagir" mais fortemente: 'Se os dados correntes já permitissem...' expressa quase que um desejo. Essa frase tornase ainda mais significativa sabendo-se, posteriormente. que o resultado da reunião foi uma votação dividida, com cinco membros votando pelo aumento da taxa $\mathrm{em} 0,25$ ponto e três membros votando pelo aumento da taxa $\mathrm{em} 0,5$ ponto. Talvez esses três sejam aqueles que estão enxergando que os sinais de descontrole inflacionário já estariam presentes.

O final da parte deliberativa da Ata (que é seguida por um Sumário dos dados analisados pelo Copom) traz um exemplo claro de discurso performativo: 'Diante disso, o Copom decidiu, por 5 votos a 3, aumentar a meta para a taxa Selic para 16,25\% a.a., sem viés'. No instante anterior. a taxa era de 16\%. Após enunciado o discurso, a taxa passou a ser $16,25 \%$. Isso ocorre porque se tratou de uma decisão tomada em um órgão governamental com a competência para tomar tal decisão. O discurso da Ata, nesse momento, é um discurso instituinte, a partir daquele momento, há uma nova realidade, a convivência com uma taxa de juros de $16,25 \%$ ao ano, sem viés.

Isso só é possível porque existe uma norma que prevê tal fato: a Circular do Banco Central n ${ }^{\circ} 3.204$, de 04 de setembro de 2003, que aprova o atual regulamento do Copom, cujo art. $4 .^{\circ}$ diz que 'Cabe aos integrantes do Copom o exercício das seguintes atribuições e competências: I - Presidente e Diretores: avaliar as propostas, acrescentar proposições acerca das questões apresentadas e definir, por meio de voto, a meta da Taxa SELIC e seu eventual viés'.

\section{Repercussão da decisão na midia}

Foram analisados dois jornais, a Folha de S. Paulo, como veículo de circulação massiva, e o Valor Econômico, como mídia especializada, no dia 16/09/04, o dia imediatamente posterior à reunião. Fundamenta-se a distinção entre mídia massiva e especializada pelas características do público a ser atingido, assim como pelo tratamento dado à notícia. Neste caso, ora em análise, tem-se uma temática que, embora tenha reflexo na vida de todo cidadão, envolve um linguajar muito específico. em campo cujos comentários ficam restritos a uma pequena parcela da população. aquela que tem afinidade com os números e as contas. 
'Hoje, estamos cada vez mais convictos de que o midium não é simples "meio" de transmissão do discurso, mas que ele imprime um certo aspecto a séus conteúdos e comanda os usos que dele podemos fazer'. (MAINGUENEAU, 2001, p. 71).

Assim, a Folha de S.Paulo tem o compromisso de abordar o assunto, de certa forma de traduzi-lo ao seu público mais massivo, haja vista as consequiências desta resolução no comércio e na vida financeira. Quanto ao Valor Ėconômico, resultante da fusão dos grupos Folha e Globo autointitulado como 'um jornal feito por quem mais entende de economia e negócios no Brasil e no mundo', existe uma identificação total do veículo com o tema em pauta. Vale ressaltar que a mídia trabalhou a partir um comunicado à imprensa e não da Ata propriamente dita, que só viria a ser publicada uma semana depois.

No Valor Econômico, a decisão foi manchete principal da capa do jornal: 'BC inicia ciclo de alta de juro com aumento de 0,25 ponto'. Foi também manchete principal do caderno de Finanças: 'Copom cumpre ameaça e sobe juro. Linha fina: Novo arrocho: BC eleva Selic para 16,25\% e alega que isso preserva o crescimento sustentado'.

Antes de analisar esta reportagem, merecem destaque outras manchetes do caderno Finanças, no mesmo dia: 'Juro mais alto pode travar consumo' (título de coluna), 'Taxa real se "perpetua" acima dos $9 \%$ ano', 'Dissensão no Copom estimula nervosismo' (título de coluna), 'Decisão de subir os juros injeta mais $\mathrm{R} \$ 1$ bi na dívida pública em 12 meses', 'Taxa dos EUA pode ir a 2\%', 'Se o aumento de juros [no Brasil] não é para travar o crescimento, então só pode ser pura sacanagem' (olho de uma entrevista com Rubéns Ricupero, ex-Ministro da Fazenda).

O juro é algo que vai travar a economia, já se tornou algo perpétuo, aumenta a dívida do governo em RS 1 bi, é muito maior do que a de $\mathbf{2 \%}$ dos americanos. Para completar o mosaico, o caderno é encerrado com uma matéria de página inteira cujo título é 'Para FMI, bancos estão no melhor da forma. Linha fina: Fundo avalia que o sistema financeiro suportou bem a tendência de alta dos juros'. Essa taxa de juros só serve mesmo para manter os bancos e seus donos, os banqueiros, em sua melhor forma, em conluio com os amigos do FMI. O efeito de sentido alcançado pelo caderno, de uma forma geral, impressiona por sua força e articulação. É possível, desta forma, avaliar que o sentido depende de toda uma rede construída pelo veículo, ou seja, o ponto de vista abordado não é específico da matéria analisada, o que justifica a importância de se conhecer as condições de produção para uma análise do discurso:

De acordo com MAINGUENEAU (2001, p. 53), 'o discurso é 'orientado' não somente porque é concebido em função de uma perspectiva 
assumida pelo locutor, mas também porque se desenvolve no tempo, de maneira linear. O discurso se constrói, com efeito, em função de uma finalidade, devendo, supostamente, dirigir-se para algum lugar'.

$\mathrm{Na}$ reportagem analisada, que foi capa do caderno finanças, temos como título: 'Copom cumpre ameaça e sobe juro'. Cumprir uma ameaça é realizar algo ruim. Ameaça pode ser 'ação, gesto ou palavra que intimida; promessa de castigo ou malefício; prenúncio ou indício de acontecimento mais ou menos perigoso ou maléfico; constrangimento imposto a alguém; intimação, cnação ${ }^{81}$ ' ou até mesmo um crime, caracterizado pela 'produção de justo receio de que algum ato ou fato lesivo venha a ocorrer ${ }^{x 2}$ '. A Linha fina: Novo arrocho - em destaque, o fato de que a decisão é mais um "arrocho", uma circunstância difícil; repressão, contrariedade; situação de emergência que exija sacrifícios, especialmente os de ordem financeira ${ }^{83}$.

Continuando a linha fina: ' $\mathrm{BC}$ eleva Selic para $16,25 \%$ e alega que isso preserva o crescimento sustentado'. Difícil não perceber o tom de ironia na afirmação, jogando com todo o sentido coletivamente construído de que os juros são o vilão econômico, coloca-se o Banco Central na posição de quem faz uma maldade, mas diz que é para o bem.

Logo no início da matéria, seguindo-se à afirmação de que o Banco Central tinha subido os juros, afirma-se que ele 'deixou claro desde já que promoverá novos apertos na política monetária em suas próximas reuniões'. Aquele que cumpriu sua ameaça desta vez poderá fazê-lo novamente na próxima, trazendo mais "aperto" para a população.

Afirmando pautar-se em um 'breve comunicado divulgado depois da reunião', o autor da reportagem deixa transparecer um certo sentido de 'desprezo da autoridade' pelo público, transmitindo apenas um "breve" comunicado, quando se trata de assunto de grande importância para toda a população.

$O$ autor da reportagem se vale da ambigüidade dos indicadores econômicos para qualificar a decisão do Banco Central como paradoxal: 'Desde julho o Copom vinha alertando a possibilidade de alta nos juros, argumentando que, por mais paradoxal que pareça, a medida iria preservar o crescimento da economia'. O Banco Central argumenta, mas a decisão continua sendo paradoxal, ou seja, apresenta uma contradição em seus termos. No que se refere à seleção lexical para a elaboração do texto, em especial das manchetes, convém destacar o pensamento de Cânara Júnior (1983. p.132) de que não há sinônimos perfeitos, ou seja,

...duas ou mais palavras podem ser de significação mais ou menos equivalente, constituindo o que se chama à sinonímia. ...A significação, do ponto de vista intelectivo, pode ser praticamente a mesma; mas há diferenças de outra ordem, em virtude daquela série de associações que a palavra carreia e que pesam no seu efeito. 
Portanto, o fato de se escolher uma ou outra palavra é pertinente para marcar o posicionamento do escritor em relação ao fato abordado. A linguagem aparece, então, como a possibilidade da subjetividade e o discurso como provocando a emergência desta subjetividade. É o locutor no exercício do discurso que, ao se apropriar das formas que a linguagem propõe, constrói sua visão de mundo sobre o tema abordado, na perspectiva de envolver o leitor. 'Todo texto se inscribe en una situación comunicativa, que está determinada entre otras cosas por el propósito de lograr una finalidad que dẹtermina el tipo de influencia que la instancia de enunciación quiere tener sobre la de recepción' (CHARAUDEAU, 2003, p.155).

A reportagem usa o recurso da polifonia, entendida no sentido literal da presença de várias vozes no texto, dando voz a alguns dos agentes da sociedade, supostamente mais bem informados (ou mais afetados) pela decisão. Um executivo de um banco afirma: 'O BC parece ter um grau de preocupação com as variáveis econômicas mais observadas, por ele maior do que o percebido pelos analistas'. Interessante essa frase, pois, deixa transparecer a percepção de um sentimento, já comentado anteriormente, de arrogância e superioridade intelectual dos membros do Copom, que, "clarividentes", estariam tentando ser mais realistas do que o rei. E o Presidente da FIESP, Horácio Lafer Piva, afirma: 'Não se sabe onde os juros vão parar'. Apesar de calcada na informação de que o Banco Central estaria apenas iniciando um movimento de alta dos juros, essa afirmação não deixa de ser exagerada, sobretudo diante de um aumento de 0,25 ponto. E Marcos Andrade, da Associação Brasileira de Indústrias de Equipamentos e Serviços para o Varejo, afirma que 'a decisão representa um balde de água fria para o varejo'.

A reportagem não ouviu autoridades do governo ou do Banco Central, o que nos leva a observar que a seleção de vozes que o veículo faz para estarem presentes no texto depende, evidentemente, do viés que se pretende construir na abordagem do tema. Convém, portanto, entender que polifonia, conceito desenvolvido por Oswald Ducrot e utilizado também por Bakhtin, pode ser tomado de formas diferentes:

O diálogo é condição da linguagem e do discurso, mas há textos polifônicos e monofônicos, segundo as estratégias discursivas acionadas. No primeiro caso, o dos textos polifônicos, as vozes se mostram; no segundo, o dos monofônicos, elas se ocultam sob a aparência de uma única voz. (BARROS, 2003, p.6).

Na Folha de S. Paulo, a decisão também foi manchete principal da capa do jornal: 'BC sobe juros e diz que é apenas o início'. Linha fina: 'Primeira elevação desde fevereiro de 2003 coloca a taxa em 16,25\% ao ano; para Fiesp, decisão freia consumo e investimento'. Dizer que algo é apenas o início é uma frase notoriamente carregada de um sentido negativo ${ }^{84}$, deixando nas 
entrelinhas, a informação pressuposta de que dias piores virão. A folha optou por fazer uso da polifonia já na capa, cedendo espaço à Fiesp para dizer que a 'decisão freia consumo e investimento'.

A capa do caderno Folha Dinheiro traz como manchete principal 'BC inicia ajuste e juros sobem para 16,25\%. Linha fina: Tensão pós-Copom Elevação da taxa é a primeira em 19 meses; Banco Central diz que esse é o começo de um processo de alta:

Outras manchetes do caderno Folha Dinheiro: 'Ampliação do Conselho Monetário Nacional' (título de coluna, na qual o autor defende mudanças na composição do Conselho Monetário Nacional e na política monetária), 'Precipitação ou antecipação?', 'O Banco Central não pode confundir antecipação com precipitação' (olho destacando frase de Gustavo Loyola. ex-presidente do Banco Central), 'País tem 2.' maior juro real do mundo Linha fina: Tensão pós-COPOM: Com alta de ontem, taxa vai para $9,47 \%$, atrás só da Turquia'. Novamente, um mosaico, constituidor de uma direção única para o sentido, ou seja, o texto seleciona algumas informações, de acordo com o ponto de vista valorizado, e deixa outras implícitas, para serem recuperadas pelo leitor, como explica Koch (1984, p.26):

Nenhum texto apresenta de forma explícita toda a informação necessária à sua compreensão: há sempre elementos implícitos que necessitam ser recuperados pelo ouvinte/leitor por ocasião da atividade de produção do sentido. Para tanto, ele produz inferência: isto é, a partir dos elementos que o texto contém. vai estabelecer relação com aquilo que o tex to implicita.

Na reportagem analisada, capa do caderno Folha Dinheiro, tem-se como título: 'BC inicia ajuste e juros sobem para 16,25\%. Linha fina: Tensão pós-Copom - Elevação da taxa é a primeira em 19 meses; Banco Central diz que esse é o começo de um processo de alta'. Evidencia-se que o movimento está apenas se iniciando, reforçando o sentido da manchete da capa do jornal. O uso na linha fina (e em linhas finas de outras matérias no caderno) 'Tensão pós-Copom' vincula-se a uma frase empregada pelo Presidente Lula, amplamente divulgada pela imprensa. de que "o país vivia uma TPC - a tensão pré-Copom' ${ }^{85}$, podendo ser entendida como uma tentativa de associar mais fortemente as decisões do Copom ao governo Lula ou mesmo "dar o troco" ao Presidente, como quem diz, "viu, o senhor disse que era brincadeira e na verdade é sério". Tem-se no uso da expressão "pós-copom" ou "pré-copom", conforme a construção do presidente, o emprego da intertextualidade, fazendo alusão à conhecida expressão TPM, síndrome vivenciada pelas mulheres e, neste contexto, também subestimada pelo presidente. Tal leitura leva-nos a lembrar que 
o discurso, seja qual for, nunca é totalmente autônomo. Suportado por toda uma intertextualidade, o discurso não é falado por uma única voz, mas por muitas vozes, geradoras de muitos textos que se entrecruzam no tempo e no espaço, a tal ponto que se faz necessária toda uma escavação "filológico-semiótica" para recuperar a significação profunda dessa polifonia. (BLIKSTEIN, 2003, p.45).

A reportagem da Folha de S. Paulo buscou demonstrar que a decisão não tinha apoio unânime entre os membros do governo, assumindo uma conotação mäis política, enfatizando os expoentes governistas a favor (Antonio Palocci Filho e Guido Mantega) e os contrários (José Dirceu e José Alencar). Essa opção política reforça o uso da expressão "tensão pré-Copom" e a associação da decisão ao governo como um todo.

A Folha também se valeu do recurso da polifonia, dando voz à Fiesp"A Fiesp disse, por meio de nota, que a decisão de ontem pode colocar um "pé no freio" na retomada do consumo e dos investimentos', e à Federação do Comércio Paulista - 'A Fecomercio SP classificou a decisão como um "retrocesso".

\section{Considerações finais}

A presente análise parte do pressuposto de que toda realidade transformada em linguagem é uma forma de interpretação ou uma representação desta realidade, portanto, é impossível uma análise de discurso com abordagem estritamente lingüística, há què se considerar as condições de produção dos textos. Neste sentido, a análise do discurso representa uma nova abordàgem do estudo do texto além da linearidade, relacionando enunciado e enunciação como elementos fundamentais da produção de sentido. A abordagem interna do texto leva-nos a reconhecer os mecanismos e regras de engendramento do discurso e a análise externa, a reconstituição do contexto sócio-histórico, permite-nos entender a construção dos sentidos de cada abordagem.

Pode-se observar que entre o texto da Ata do Copom, pretensamente objetivo e formal, e a interpretação que a mídia faz do mesmo, seja a mídia massiva, seja a especializada, ocorre, nitidamente, um confronto de sentidos. Embora os assuntos econômicos e as decisões dos órgãos governamentais, como no caso analisado, tenham consequiências diretas sobre a vida do cidadão, recebem, no nosso país, pouca atenção por parte da população em geral. Criou-se, de certa forma, um estereótipo de que se trata de um assunto muito complicado, que envolve números e cálculos, portanto, é inacessível e intraduzível ao leitor comum. Entende-se o fato de a ata do Copom ser redigida em linguagem formal e impenetrável, pois, é dirigida a um público restrito e especializado. Porém, espera-se que a cobertura midiática possa traduzir estès dados ao leitor, informando e cumprindo seu papel social. 
As reuniões do Copom têm sido sistematicamente acompanhadas e cobertas pela mídia, como ocorre, aliás, em outras partes do mundo, entendendo-se que as decisões deste conselho, inevitavelmente, acarretarão alterações na vida financeira da população.

A análise atenta da Ata do Copom mostra um discurso inflexível e autoritário, como forma de justificar a legitimidade das decisões tomadas. Da mesma forma, pode-se observar uma tendência de transparecer a inexorabilidade da ação do Copom, como que a transferir a "culpa" de uma decisão "ruim" para entes abstratos, como tendências inflacionárias, comportamento de variáveis da política monetária, entre outros. O texto é composto de afirmativas categóricas, transmitindo um sentido de certeza absoluta.

Foram analisados dois jornais, a Folha de S. Paulo, como veículo de circulação massiva, e o Valor Econômico, como mídia especializada, no dia 16/09/04, o dia imediatamente posterior à reunião, quando a Ata ainda não havia sido publicada, ou seja, a mídia trabalhou, neste dia, a partir de um comunicado à imprensa e não do documento oficial.

As características editoriais de cada jornal, assim como compromisso que cada um deles estabelece com o leitor, determinaram diferentes abordagens do assunto: a reportagem da Folha de S. Paulo buscou demonstrar que a decisão não tinha apoio unânime entre os membros do governo, assumindo uma conotação mais política, aliviando, de certa forma, a aspereza do próprio assunto em pauta, quando destaca, por exemplo, as expressões "tensão pré-copom e pós-copom", cunhadas pelo presidente na tentativa de amenizar o impacto das repercussões das decisões do Conselho. O Valor Econômico concentrou-se em uma análise mais centrada nos aspectos financeiros e econômicos que envolvem as decisões tomadas pelo Conselho, ironizando o fato de o aumento de juros ser a melhor solução para o país, tratando, de forma estereotipada, os juros como o vilão econômico, o Banco Central como o opositor, aquele que faz uma maldade, mas diz que é para o bem, e o povo como o grande sacrificado.

\section{Referências Bibliográficas}

BACCEGA, Maria Aparecida. Comunicação e Linguagem - Discursos e Ciência. São Paulo: Moderna, 1998.

BAKHTIN, Mikhail. Estética da Criação Verbal. São Paulo : Martins Fontes, 1997.

BARTHES, Roland. O rumor da língua. São Paulo: Brasiliense, 1987. 
BARROS, Diana Luz Pessoa de. Dialogismo, Polifonia e Enunciação. In BARROS, Diana Luz Pessoa de; FIORIN, José Luiz (orgs). Dialogismo, Polifonia, Intertextualidade. $2^{\text {a }}$ ed. São Paulo : Edusp-Editora da Universidade de São Paulo, 2003.

BARROS, Diana Luz Pessoa de. Teoria do Discurso - Fundamentọ Semióticos. $3^{\text {a }}$ ed. São Paulo : Humanitas FFLCH/USP, 2002.

BLIKSTEIN, Izidoro. Intertextualidade e Polifonia - O discurso do Plano "Brasil Novo". In BARROS, Diana Luz Pessoa de; FIORIN, José Luiz (orgs). Dialogismo, Polifonia, Intertextualidade. $2^{\mathrm{a}}$ ed. São Paulo : Edusp - Editora da Universidade de São Paulo, 2003.

CAMARA Júnior, Joaquim Mattoso. Manual de Expressão Oral e Escrita. $7^{\mathrm{a}}$ ed. Petrópolis : Vozes, 1983.

CHARAUDEAU, Patrick, El Discurso de la Información - La construcción del espejo soçial. Barcelona : Gedisa Editorial, 2003,

DICIONÁRIOELETRÔNICO HOUAISS. São Paulo: Objetiva, 2002.CD-ROM. KRISTEVA, Julia. História da Linguagem. Lisboa : Edições 70, 1988.

KOCH, I. V. Argumentação e Linguagem. São Paulo: Cortez, 1984.

MAINGUENEAU, Dominique. Análise de Textos de comunicação. $2^{\mathrm{a}}$ ed, São Paulo : Cortez, 2002.

ORLANDI, Eni P. A linguagem e seu funcionamento: as formas do discurso. 2. ${ }^{a}$ ed. Ver. Campinas: Pontes, 1987.

ORLANDI, Eni P. Análise de Discurso - Princípios \& Procedimentos. 5. ed.

132 Ver. Campinas: Pontes, 2003.

PÊCHEUX, Michel. O discurso: Estrutura ou Acontecimento (Trad. Eni Puccinelli Orlandi), Campinas, SP : Pontes, $3^{\mathrm{a}}$ ed,, 2002.

PINTO, M. J. Comunicação e Discurso. São Paulo: Hacker Editores, 1999.

SANTAELLA, L. Produção de linguagem e ideologia. São Paulo: Cortez, 1996. VAN DIJK, Teun A. Cognição, discurso e Interação. São Paulo : Contexto, 1992.

\section{Notas}

${ }^{1}$ Disponível em www.bcb.gov.br.

${ }^{2}$ Valor Econômico, 13/09/2004, "Copom chega à 100, " zeunião e gạnha importância".

${ }^{3}$ Idem.

${ }^{4}$ www.bcb.gov.br, acessado em 3 de novembro de 2004.

${ }^{5}$ www.bcb.gov.br, acessado em 4 de novembro de 2004.

${ }^{6}$ A controvérsia entre os economistas é tamanha que chega ao ponto de alguns defenderem a indeterminabilidade a priori da taxa de juros praticada, tendo em vista a mesma ter vigência em um regime de nominalismo econômico. Em princípio, para se saber a taxa real de juros, 
há que se esperar um ano, para se fazer o desconto da inflação do período.

${ }^{7}$ Dicionário Eletrônico Houaiss, 2002.

${ }^{8} \mathrm{Idem}$.

${ }^{9} \mathrm{Ibdem}$.

${ }^{10} \mathrm{~A}$ frase "isso é apenas o início" pode ser usada com conotação positiva, logicamente, porém, considerando-se o contexto referencial em que foi empregada, bem como o consenso existente na mídia de que os juros são algo ruim, o vilão econômico da atualidade. percebe-se a colocação da frase no título da matéria com uma conotação evidentemente negativa.

"Veja, 22 de setembro de 2004, "Cão que ladra morde", pp. 56-57. A própria expressão de Lula é carregada de sentido, remetendo à Tensão PréMenstrual, amplamente conhecida do imaginário popular como algo ruim. que deixa as mulheres instáveis e nervosas. 
